\title{
Aspects concerning the influence of the design of flameproof electric motors on maximum explosion pressures
}

\author{
Mihai Magyari*, Lucian Moldovan and Diana Sălășan \\ National Institute for Reasearch and Development in Mine Safety and Protection to Explosion - \\ INSEMEX Petroșani, 32-34 G-ral. Vasile Milea street, Petroşani, Hunedoara county, Romania
}

\begin{abstract}
The research carried out in the specialized Laboratory of the National Institute for Research and Development in Mine Safety and Explosion Protection - INSEMEX Petrosani has identified as causes for the occurrence of high pressure peaks in the case of electric motor enclosures, the internal volume, the geometrical shape of motor enclosures and the very intricate and complex internal arrangement of such motor enclosures (especially in the case of large motor enclosures), having in mind the tendency of motor manufacturers for chemical and petrochemical industry to manufacture motors having more complex geometrical shapes.
\end{abstract}

\section{Introduction}

The purpose of the paper is to study the way in which the internal volume, the dimensions, the geometrical shape, as well as the internal arrangement of explosion protected flameproof large rotating electrical machine enclosures, influence the maximum explosion pressures and the explosion pressure development, when tested in explosive mixtures of gases and vapors.

The research carried out has proved to be very useful in assisting designers of large flameproof electric motors to improve the motors design in order to make them more reliable when tested in explosive mixtures, as it is not yet very clear to what extent the above mentioned elements influence the explosion pressure development when testing these motors in explosive mixtures, for certification purposes.

The electric motors with type of protection flameproof enclosure have to withstand the following type tests and verifications, in order to be certified having in view their placing on the market:

- reference pressure determination and overpressure test;

- test for non-transmission of an internal ignition.

The most important subassemblies of flameproof enclosure motors that provide the type of protection Ex d, are: stator casing, shields, rotor, fan and fan hood, terminal box, terminal box cover, as shown in Fig. 1.

*Corresponding author: mihai.magyari@insemex.ro 


\section{Methods and research used}

The basic methods used in the laboratory are:

a) Determination of the maximum explosion pressure (reference pressure) that can be developed inside the motor enclosure, depending on which group / subgroup of gases the motor is designed for. All motors are tested in the laboratory using three pressure transducers type KISTLER 6031; 3 charge amplifiers type KISTLER 5011, 2 osciloscopes type HP 54645A, as well as three ignition devices (spark plugs), each located in the endturn area at each end of the motor and under the terminal plate of the terminal box.

For normal enclosures, the explosion pressure is reasonably uniform within the enclosure. However, when an enclosure incorporates some form of restriction between the two parts the situation changes [1].

When an explosion occurs on one side of the restriction, the gas or vapour on the other side is compressed prior to ignition by the flame front. This leads to a higher pressure than when no restriction is present [1].

Based on our experience (research conducted in the specialized laboratory of INSEMEX), often, the maximum explosion pressure is recorded under the terminal plate of the motor to the pressure piling phenomenon. Ignition is initiated at each end of the motor and from under the terminal plate, in turn, with the motor both at rest and when running [2, $3]$.

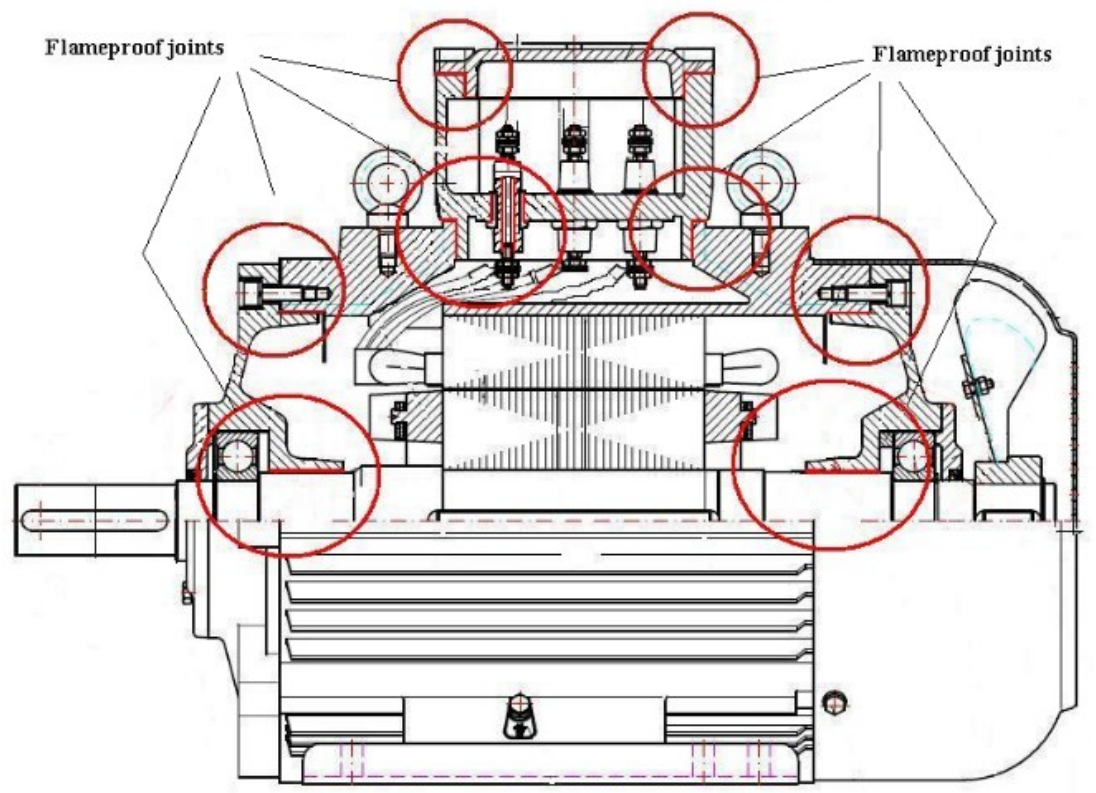

Fig. 1. Flameproof enclosure motor assembly

Fig. 2 shows an example of explosion pressure diagram where very high explosion peaks have been observed during testing of a large motor.

The phenomenon of pressure piling is of critical importance for flameproof enclosures as it is responsible for the high peak pressure values recorded in Ex d motor enclosures and has to be specifically addressed by motor manufacturers.

Pressure piling is defined as being the result of an ignition in a compartment or a subdivision of an enclosure, of a gas mixture precompressed, for example, due to a primary ignition in another compartment or subdivision 


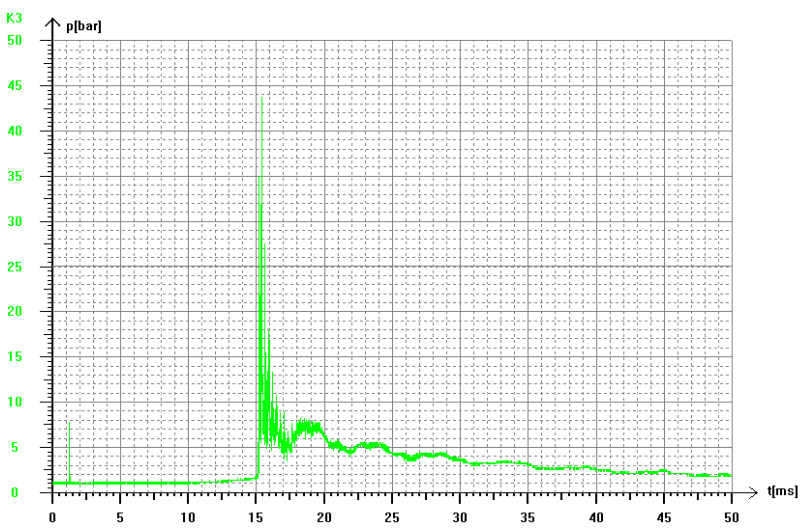

Fig. 2. Extremely high pressure recorded

However, there are other factors involved than just the pre-compression, this meaning that the pressure piling phenomenon is the result of the combination of: (1) the precompression effect arising from the jet flow from the ignition vessel; (2) the turbulence induced by the fast flame propagation (jet ignition) in the secondary vessel; and (3) the vent flowing toward the ignition vessel, which mitigates the peak pressure [1].

Fig. 3 below shows the process diagrammatically; with an ignition in the left-hand compartment pressurizing the gas/air mixture in the right-hand compartment which once ignited creates a higher pressure [1].

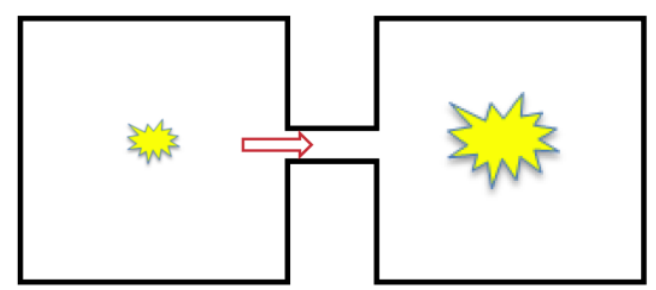

Fig. 3. Pressure piling

Pressure piling is of relevance to flameproof motors incorporating an air gap between the stator and rotor, because this can often provide the conditions necessary for pressure piling to occur. Other communications paths can also occur, such as cooling ducts or open connections to the terminal box [1].

Having in mind that the maximum explosion pressures as a result of pressure piling cannot be foreseen, the motor enclosure should be designed assuming that pressure piling will occur and the manufacturer should have in mind the recommendations regarding the avoidance of this phenomenon, described in the following paragraphs $[1,2,3]$.

b) Overpressure tests, which are carried out in our laboratory using the dynamic method. During these tests the ability of the motor enclosure to withstand 1.5 times the reference pressure recorded during the previous tests, is verified.

The tests in both a) and b) cases are of paramount importance for the motor manufacturer, as the motor enclosure must be designed in such a way as to withstand 1.5 times the reference pressure. 


\section{Results obtained}

After carrying out this research, the causes for the occurrence of high pressure peaks in the case of large electrical motor enclosures have been identified: the extremely large internal volume, the geometrical shape of the motor enclosures, having in mind the latest tendency of motor manufacturers for the chemical and oil and gas industry to manufacture motors with highly complex geometrical shapes, due to the cooling and mounting methods, as well as the internal arrangement of these motors, which differ from the classical ones and from small frame size motors.

The main causes for the occurrence of pressure peaks in the case of large rotating electrical machines have been found to be the following $[3,4]$.

\section{a) The geometrical shape of the motor enclosure}

The geometrical shape of the motor enclosures plays an important role especially if the ratio between the length of the enclosure and the cross-sectional dimensions is significant. In this case, when the burning is initiated from one end side of the motor, the flame front can be accelerated across the length of the enclosure, being capable even of making the transition from deflagration to detonation in certain extreme cases [3].

As far as designing pressures are concerned in this case, we recommend that the ratio between the length of the enclosure and the smallest cross section dimension not to exceed the value of 4 . For values of this ratio, of less than 4 , the occurrence of pressure peaks is unlikely, unless there are other factors which can generate it.

b) Precompression of the testing mixture (the internal arrangement / division of the motor enclosure)

The precompression of the testing mixture is one of the main causes for pressure peaks occurrence. These pressure peaks occur mostly in the smaller volume subdivision after the ignition took place in the higher volume subdivision. The small surfaces or the passages which connect the two subdivisions increase the likelihood of pressure peaks occurrence. If there are a series of subdivisions connected to each other, the explosion pressure will tend to increase as the flame front propagates from one subdivision to another, reaching the maximum value in the last subdivision $[2,3]$.

As regards designing solutions, in case subdivision cannot be avoided, which is the case of motor enclosures (and not only), then the precompression that takes place in the second subdivision, before the ignition of the testing mixture occurs, can be estimated as being the final explosion pressure in the first subdivision.

\section{c) The type of gas used and the explosive mixture concentration}

Gases like hydrogen, acetylene and even ethylene which can sometimes produce higher pressures than hydrogen, when pressure piling is an issue, due to its lower flame speed propagation, can produce higher explosion pressures and have a higher tendency to generate higher explosion peaks; also, a concentration which is near to the stoichiometric concentration is likely to result in much higher explosion pressures [2]. It is true though, that when pressure piling occurs, slower flame speeds of non-stoichiometric mixtures can lead to higher pressures due to higher precompression before ignition in the second compartment.

d) Flame front acceleration and flame front instability

The designer should reduce the likelihood of flame front acceleration, taking into account the indications concerning the design of subdivided enclosures and by minimizing the obstacles in the mixture flow path that can generate turbulence. The designer will not be able to eliminate the required apparatus inside the enclosure, nor will he be able to always eliminate the potential turbulence generators. The designer has to focus mainly on avoiding enclosure subdivision (where possible) by carefully arranging the inner apparatus and, in case enclosure subdivision cannot be avoided, the designer has to eliminate the obstacles 
which are not necessary or the restrictions on the passages between different enclosure subdivisions $[3,5]$.

Below we present some experimental results obtained in the laboratory. The first example (Table 1, together with the corresponding Fig. 4) relate to a motor, manufactured by Electroputere Craiova, type MIB 450 100-4, $450 \mathrm{~kW} ; 690 \mathrm{~V}$ a.c., $1500 \mathrm{rpm}$ ) where no changes related to the design have been operated by the manufacturer, this leading to very high pressure peaks, while the other two examples (Table 2 and Table 3 and the corresponding Figs. 5 and 6) are due to the changing of the motor design, this meaning an increased air gap between stator and rotor (from $1.5 \mathrm{~mm}$ to $3 \mathrm{~mm}$ ) and an increased area of the aperture for the passage of winding conductors to the terminal plate. Tests have been carried out both with hydrogen and acetylene, but in the next tables only the results with acetylene have been shown (because of the limits required for the presented paper). The test method used is according to IEC 60079-1: 2014, art. 15.2.2. The laboratory setup included: 3 pressure transducers type KISTLER 6031; 3 charge amplifiers type KISTLER 5011, 2 osciloscopes type HP 54645A, Oxygen analyser type Servomex 2200, Multimeter type Agilent 34970A.

Table 1. Very high pressures recorded, reference pressure test

\begin{tabular}{|c|c|c|c|c|c|c|c|}
\hline No. & $\begin{array}{c}\text { Ignition } \\
\text { place }\end{array}$ & $\begin{array}{c}\text { Precompression } \\
\text { of test mixture } \\
{[\text { bar] }}\end{array}$ & $\begin{array}{c}\text { Percentage } \\
\text { of gas in } \\
\text { air }\end{array}$ & $\begin{array}{c}\text { Temperature } \\
{\left[{ }^{\circ} \mathrm{C}\right]}\end{array}$ & $\begin{array}{c}\text { P1 } \\
{[\text { bar }]}\end{array}$ & $\begin{array}{c}\text { P2 } \\
{[\text { bar }]}\end{array}$ & $\begin{array}{c}\text { P3 } \\
{[\text { bar }]}\end{array}$ \\
\hline 1 & 1 & 0.95 & 14.03 & 23.53 & 0.00 & 0.00 & 11.17 \\
\hline 2 & 1 & 0.95 & 14.03 & 23.27 & 0.00 & 0.00 & 19.92 \\
\hline 3 & 1 & 0.95 & 14.03 & 23.04 & 0.00 & 0.00 & 19.92 \\
\hline 4 & 1 & 0.95 & 14.08 & 22.83 & 0.00 & 0.00 & 19.92 \\
\hline 5 & 1 & 0.95 & 14.03 & 22.69 & 0.00 & 0.00 & 43.75 \\
\hline
\end{tabular}

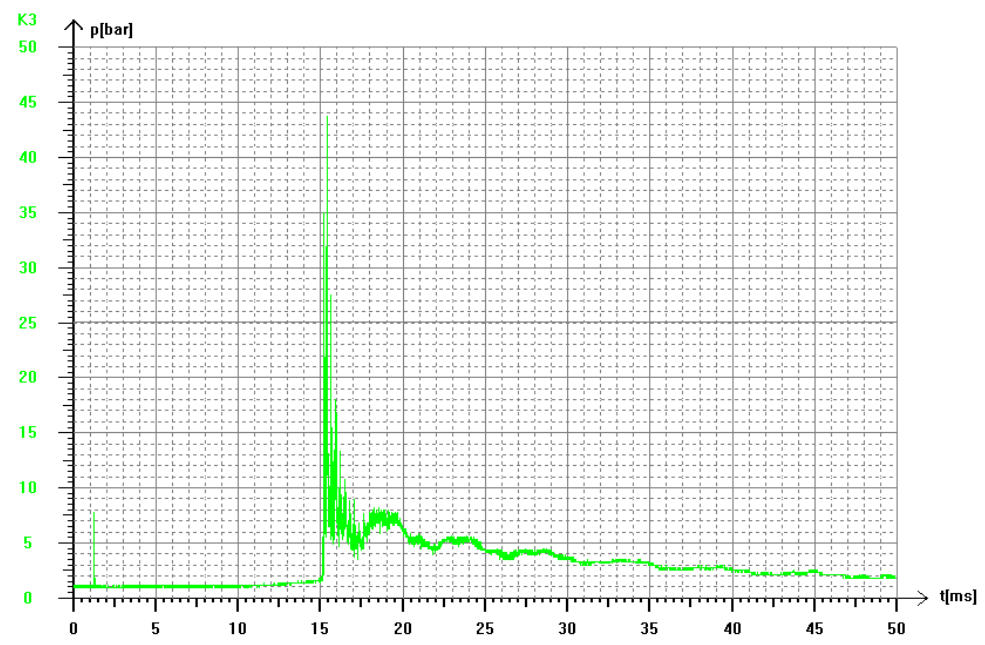

Fig. 4. Very high pressure measured under the terminal plate of the terminal box (acetylene) 
Table 2. Lower pressures recorded, reference pressure test

\begin{tabular}{|c|c|c|c|c|c|c|c|}
\hline No. & $\begin{array}{c}\text { Ignition } \\
\text { place }\end{array}$ & $\begin{array}{c}\text { Precompression } \\
\text { of test mixture } \\
{[\text { bar] }}\end{array}$ & $\begin{array}{c}\text { Percentage } \\
\text { of gas in } \\
\text { air }\end{array}$ & $\begin{array}{c}\text { Temperature } \\
{\left[{ }^{\circ} \mathrm{C}\right]}\end{array}$ & $\begin{array}{c}\mathrm{P} 1 \\
{[\text { bar }]}\end{array}$ & $\begin{array}{c}\mathrm{P} 2 \\
{[\text { bar }]}\end{array}$ & $\begin{array}{c}\mathrm{P} 3 \\
{[\text { bar }]}\end{array}$ \\
\hline 1 & 2 & 0.93 & 14.08 & 19.47 & 8.59 & 5.16 & 6.72 \\
\hline 2 & 3 & 0.93 & 13.94 & 19.44 & 5.51 & 5.47 & 3.87 \\
\hline 3 & 2 & 0.93 & 14.12 & 19.42 & 9.96 & 4.92 & 7.34 \\
\hline
\end{tabular}

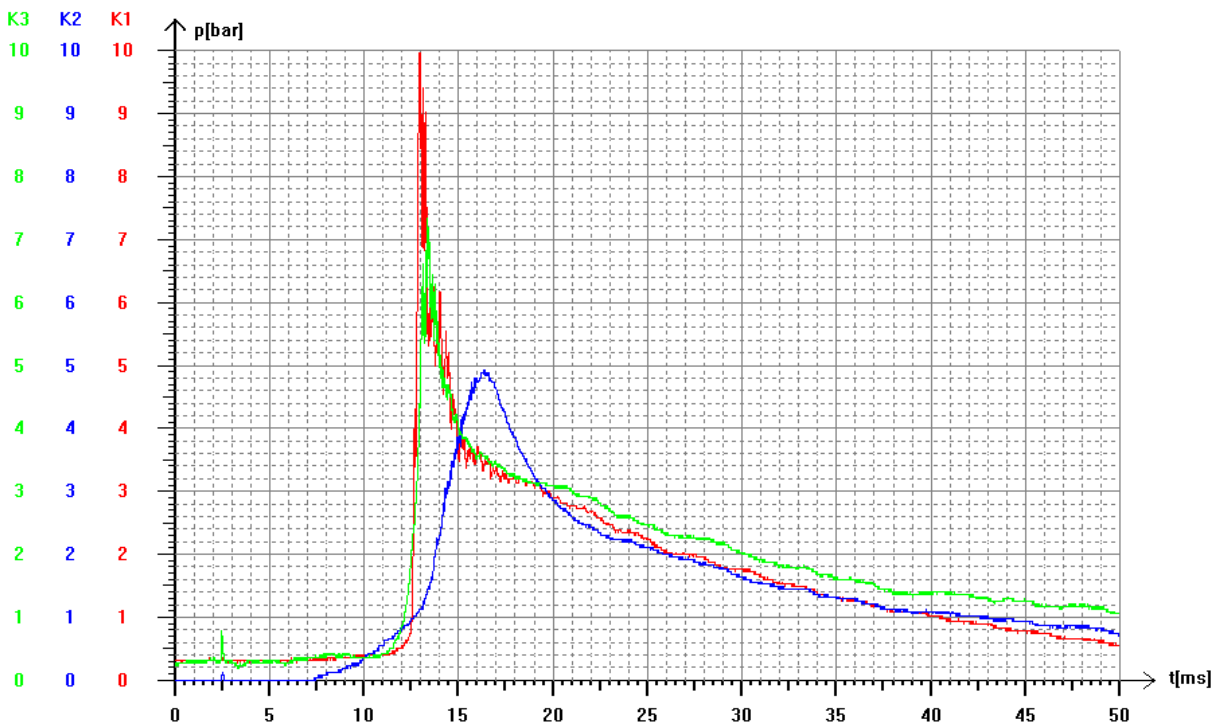

Fig. 5. Lower pressures - motor with increased air gap between stator and rotor

Table 3. Low pressures recorded, reference pressure test

\begin{tabular}{|c|c|c|c|c|c|c|c|}
\hline No. & $\begin{array}{c}\text { Ignition } \\
\text { place }\end{array}$ & $\begin{array}{c}\text { Precompression } \\
\text { of test mixture } \\
{[\text { bar] }}\end{array}$ & $\begin{array}{c}\text { Percentage } \\
\text { of gas in } \\
\text { air }\end{array}$ & $\begin{array}{c}\text { Temperature } \\
{\left[{ }^{\circ} \mathrm{C}\right]}\end{array}$ & $\begin{array}{c}\text { P1 } \\
{[\text { bar }]}\end{array}$ & $\begin{array}{c}\text { P2 } \\
{[\text { bar }]}\end{array}$ & $\begin{array}{c}\text { P3 } \\
{[\text { bar }]}\end{array}$ \\
\hline 1 & 1 & 0.95 & 13.98 & 19.36 & 3.83 & 3.87 & 1.52 \\
\hline 2 & 2 & 0.95 & 14.03 & 19.35 & 6.88 & 6.88 & 6.02 \\
\hline 3 & 3 & 0.95 & 14.08 & 19.33 & 5.12 & 5.51 & 7.23 \\
\hline 4 & 2 & 0.95 & 14.03 & 19.29 & 7.46 & 6.52 & 6.37 \\
\hline 5 & 3 & 0.95 & 14.03 & 19.29 & 4.92 & 5.31 & 7.19 \\
\hline
\end{tabular}




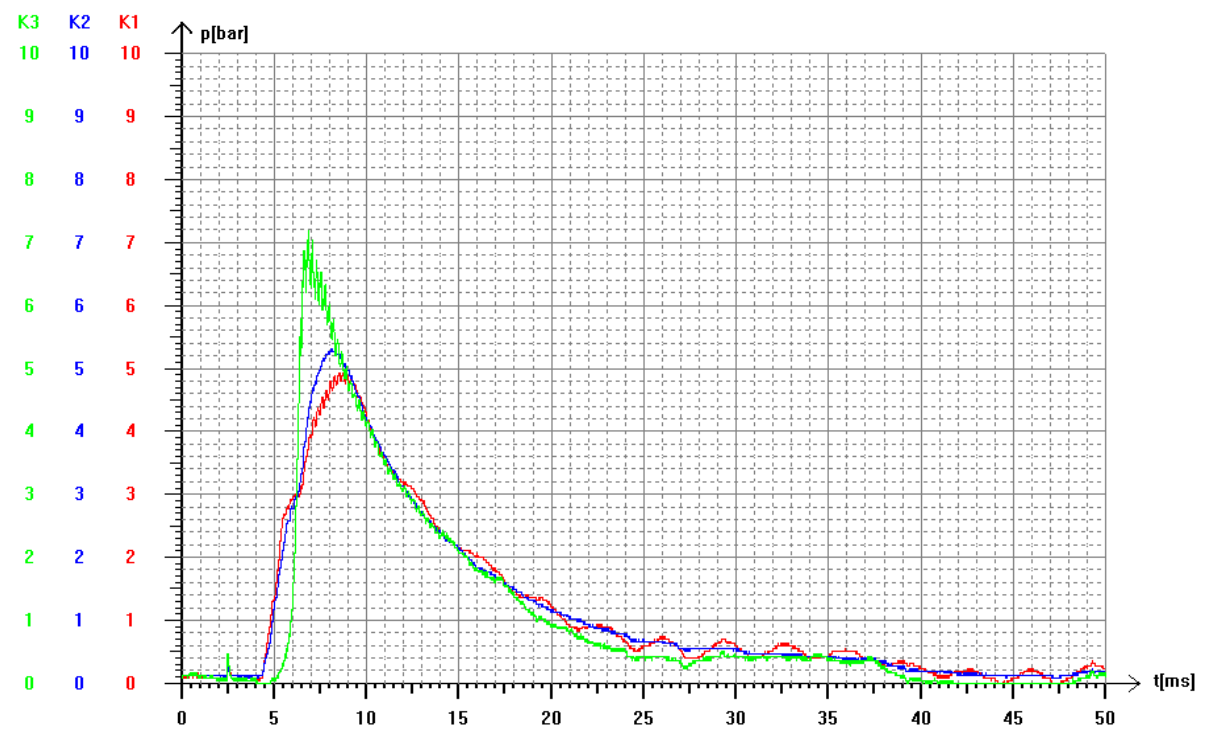

Fig. 6. Low pressures recorded in a motor

\section{Conclusions}

The research carried out in the specialized Flameproof Laboratory of INSEMEX has proved to be very useful in assisting designers of large flameproof electric motors to enhance the design of motors so as to make them more reliable when testing in explosive mixtures.

The main conclusion from this research is that by carefully designing the motor enclosure, together with its internal arrangements, although it may be impossible to prevent pressure piling from occurring, it is often possible to reduce the explosion pressure due to pressure piling, to an acceptable level, making it easier for motor manufacturers to design the enclosures, with respect to the maximum pressures that can be developed.

\section{References}

1. Munro J., Impact of extremely cold temperatures on the safety of flameproof motors $(\mathrm{PhD}$ Thesis, Faculty of Engineering and Information Technologies, The University of Sydney, Australia, 2017).

2. Magyari M., The modernization of the testing facility of the laboratory for carrying out tests in explosive mixtures for flameproof rotating electrical machines, while running, Nucleu Programme (PN 07-45-02-54) National Institute for Research and Development in Mine Safety and Protection to Explosion INCD INSEMEX Petroşani (2015).

3. Magyari M., The modernization of the facility for testing in explosive mixtures in the case of large flameproof electric motors, Nucleu Programme (PN $16-43-02-11$ ) National Institute for Research and Development in Mine Safety and Protection to Explosion INCD INSEMEX Petroșani (2017).

4. Magyari M., Burian S., Moldovan L., Fotău D., Colda C., Proceedings of the 7th International Health and Safety in Labour Symposium SESAM 2015 257-266 (2015).

5. Magyari M., Burian S., Friedmann M., Moldovan L., Environmental Engineering and Management Journal, 11, 1311-1316 (2011). 